\title{
Long-term effects of combined percutaneous atrial septal defect occlusion and pulmonary valvuloplasty in children $<2.5$ years old
}

\author{
Sebastian Smerdziński ${ }^{1,2}$, Jacek Białkowski ${ }^{1,2}$, Małgorzata Szkutnik ${ }^{1,2}$, Mateusz Knop ${ }^{1,2}$, \\ Michał Gałeczka ${ }^{1,2}$, Roland Fiszer ${ }^{1,2}$ \\ ${ }^{1}$ Department of Congenital Heart Defects and Paediatric Cardiology, Silesian Centre for Heart Diseases, Zabrze, Poland \\ ${ }^{2} \mathrm{~S}$ chool of Medicine with the Division of Dentistry in Zabrze, Medical University of Silesia, Katowice, Poland
}

\section{INTRODUCTION}

The combination of atrial septal defect (ASD) type II and pulmonary valve stenosis (PS) is a relatively uncommon congenital heart disease.

When this condition is present, significant left-to-right shunt is usually prevented by right outflow obstruction, but right ventricular (RV) hypertrophy progresses. Transcatheter pulmonary balloon valvuloplasty (PBV) and closure of the ASD are the treatment of choice [1, 2]. Combined percutaneous ASD closure and PBV is an infrequent but feasible method of treatment, mostly described in adults $[3,4]$ but also in children $[5,6]$. We present a unique group of young children, in whom the main indication for a percutaneous intervention was significant PS coexisting with important clinical ASD. The long-term outcomes of the procedure are also presented.

\section{METHODS}

Between 1999 and 2014, 157 cases of percutaneous ASD closure in children under three years old were recorded in our centre [7]. In this group, there were eight patients aged under 2.5 years old (three girls) in whom PS was simultaneously treated by PBV. In all patients, the indication for such therapy was a transpulmonary gradient $\geq 40 \mathrm{mmHg}$. The clinical data of these patients are presented in Table 1 . The mean age of the patients was 1.7 years $(0.5-2.5$ years) and mean weight was $12 \mathrm{~kg}(8.7-16.7 \mathrm{~kg})$. In all patients (apart from one), overload of right cardiac cavities was found. In seven patients, left-to-right shunt through the ASD was present. In a two-year-old child with borderline hypoplastic RV and critical PS in the neonatal period, PBV was performed with subsequent surgical left Blalock-Taussig anastomosis (Table 1, patient 7). In this child, bidirectional shunting through the ASD was observed, with an oxygen saturation of $86 \%$. In another child in the neonatal period, pulmonary valve atresia with intact ventricular septum and ASD were diagnosed and treated by perforation of the atretic valve with the stiff part of the guidewire, with subsequent PBV (Table 1, patient 5). So, in these two patients, a second PBV was performed because of restenosis. Single ASD was present in six patients, and two patients had multiple ASDs (there were small additional fenestrations located close to the main defect (Table 1, patients 4 and 8). In all cases, the extents of ASD and PS were estimated before the procedure by transthoracic echocardiography and the diagnosis was confirmed during catheterisation by transoesophageal echocardiography (TEE). The decision regarding the method of treatment (PBV and simultaneous ASD closure) was made by a paediatric surgeon and the paediatric cardiology team.

All the transcatheter interventions were performed in a haemodynamic laboratory under general anaesthesia with intubation and antibiotic coverage. Standard dose of heparin $100 \mathrm{IU} / \mathrm{kg}$ was applied before the procedure. Diagnostic right heart catheterisation was done. Thereafter, PBV was performed in a standard fashion with a Tyshak balloon as the first procedure in all patients (to avoid catheter manipulation after ASD device implantation). The balloon diameter/valvular annulus ratio was 1.1-1.4. The transpulmonary gradient was measured again immediately after PBV. ASD was closed with an Amplatzer Septal Occluder (ASO; St. Jude Medical, now Abbott Co. Plymouth, MA, USA). ASD closure was performed under fluoroscopy (mean time $11 \mathrm{~min}$ ) and TEE guidance. A necessary condition for transcatheter ASD closure was the presence of atrial septal rims (at least $5 \mathrm{~mm}$ ) in order to avoid embolisation of the device. The exception was the aortic rim, which could be deficient. The implant size was selected either on the basis of the defect stretch diameter (Table 1, patients $1,2,3,6,8)$ or with reference to the defect diameter defined by TEE (it was equal to $1 \mathrm{~mm}$ or bigger than the greatest

Address for correspondence:

Dr. Sebastian Smerdziński, ul. św. Jerzego 5/6, 41-800 Zabrze, Poland, tel: +48 728366 852, fax: +48 3227134 01, e-mail: smerdzinski@gmail.com Received: $1.09 .2018 \quad$ Accepted: 8.11.2018 Available as AoP: 9.11.2018 


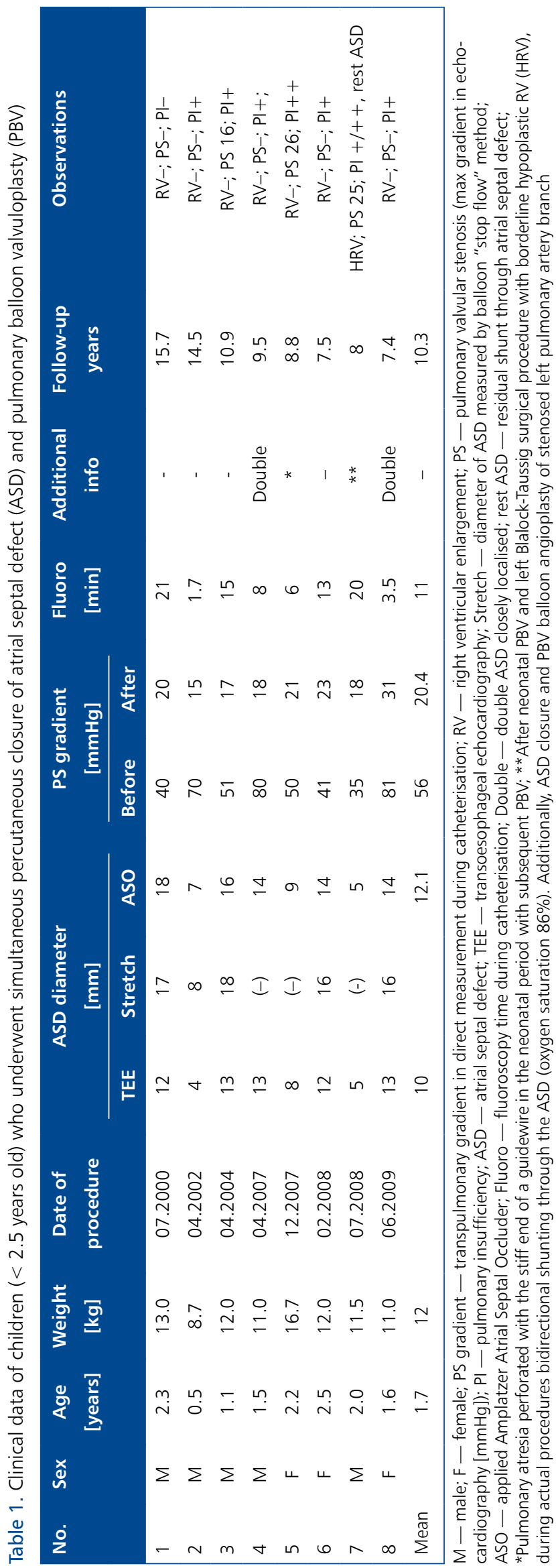

measurement in this examination [Table 1, patients 4, 5, 7]). Consequently, catheter balloon calibration was omitted in three children with centrally located defects with good surrounding rims. Each ASO was implanted in a standard fashion [8], and before its release, a precise evaluation of the implant position was made using TEE. After the procedure, acetylsalicylic acid in a dosage of 3 to $5 \mathrm{mg} / \mathrm{kg}$ daily during the first six months was prescribed. The outcomes of the interventions were evaluated after the first, third, sixth, and $12^{\text {th }}$ months, and every year when no complications occurred.

\section{RESULTS AND DISCUSSION}

All the procedures were successful, without any intraoperative or postoperative complications. Development of all treated children was excellent in follow-up of over 10.3 years (7.4-15.7 years). The mean transpulmonary gradient of $56 \mathrm{mmHg}$ (35-81 $\mathrm{mmHg}$ ) decreased to $20.4 \mathrm{mmHg}(15-31 \mathrm{mmHg})$ after PBV. In two patients, slight PS with moderate pulmonary valve insufficiency (PVI) was observed immediately after the procedure and in follow-up (Table 1, patients 5 and 7). The probable reason for PVI in both cases was a dysplastic pulmonary valve. Both patients had complex defects treated by PBV in the neonatal period. The development of the RV in the first child was adequate (Table 1, patient 5). In the second child (Table 1, patient 7), normalisation of oxygen saturation was observed, with some degree of persistent RV hypoplasia. The mean ASD diameter on TEE was $10 \mathrm{~mm}(4-13 \mathrm{~mm})$, and the mean size of the applied ASO was $12.1 \mathrm{~mm}$ (5-18 mm). The mean implant size and body weight ratio in all of the groups was 1.0 (ranging from 0.45 to 1.38). In a two-year-old child with a relatively small ASD $(5 \mathrm{~mm})$ with bidirectional shunting, saturation after the procedure permanently increased from $86 \%$ to $96 \%$ (Table 1, patient 5). Residual shunting through the ASD was present in this child (from the beginning of follow-up). In this patient, an initially double ASD was present and the second ASD was distal to the applied device. In all other patients, no residual leaks were observed.

In patient 2 (Table 1) with a 4-mm ASD estimated on TEE (stretch diameter of $8 \mathrm{~mm}$ ) and with an enlarged RV, the decision for ASD closure during pulmonary valvuloplasty procedure was made upon firm request of the parents.

The optimal time for transcatheter ASD closure in children is still an open issue. It is believed that small defects tend to close spontaneously, while the bigger ones tend to increase in size [9]. It is also believed that significant ASDs should be closed around the age of four to five years. Our experience indicates that percutaneous closure of ASD is also feasible in infants and children below three years of age [7, 8], but we have to remember that spontaneous closure of even large ASDs can occur [10].

The data presented here document that another indication for early transcatheter ASD closure is the coexistence of important PS. 
The youngest documented patient treated with these techniques was a neonate with critical PS and ASD [6]. In our study, the youngest patient was six months old, and the mean age of the treated patients was 1.7 years. In our practice, we performed PBV as the first procedure to avoid catheter manipulation after the placement of the ASD device. Other authors preferred to perform the ASD closure first (before PBV) [4] or carry out a staged procedure (postponing PBV a few days or months) [3]. Chinese authors compared 35 patients who underwent percutaneous correction of both defects with 43 patients treated surgically. All patients had simultaneous complete correction, and no serious complications occurred in either group. They stated that the transcatheter procedures of ASD closure and PBV were viable alternatives to corrective cardiac surgery [11]. Our experience of the long-term efficacy of such percutaneous procedures confirm their observations.

In conclusion, interventional technology addressing multiple simultaneous congenital cardiac defects (ASD and PS) as a combined procedure in young children $(<2.5$ years old) is safe and effective in short- and long-term observations.

\section{Conflict of interest: none declared}

\section{References}

1. Rocchini AP, Kveselis DA, Crowley D, et al. Percutaneous balloon valvuloplasty for treatment of congenital pulmonary valvular stenosis in children. J Am Coll Cardiol. 1984; 3(4): 1005-1012, indexed in Pubmed: 6707337.

2. Białkowski J. Percutaneous closure of atrial septal defect type II: a few remarks on the basis of my own experience. Kardiol Pol. 2017; 75(10): 1062-1063, doi: 10.5603/KP.2017.0198, indexed in Pubmed: 29057440.
3. Vera JA, Nounou M, Kern M. Staged percutaneous atrial septal defect closure and pulmonic balloon valvuloplasty in an adult with congenital heart disease. Catheter Cardiovasc Interv. 2008; 72(3): 416-423, doi: 10.1002/ccd.21612, indexed in Pubmed: 18727123.

4. Tomasov P, Linhartova K, Antonova P, et al. Combined percutaneous treatment of atrial septal defect and pulmonic or aortic stenosis in adult patients. Arch Med Sci. 2010; 6(6): 976-980, doi: 10.5114/aoms.2010.19312, indexed in Pubmed: 22427776.

5. Yip WC, Chan KY, Godman MJ. Simultaneous transcatheter valvuloplasty and Amplatzer septal occlusion for pulmonary valvar stenosis and secundum atrial septal defect. Ann Acad Med Singapore. 1998; 27(4): 578-581, indexed in Pubmed: 9791671.

6. Nugent AW, Menahem S, Goh TH, et al. Device closure of an atrial septal defect following successful balloon valvuloplasty in a neonate with critical pulmonary valve stenosis and persistent cyanosis. Pediatr Cardiol. 2000; 21(2): 170-171, doi: 10.1007/s002469910030, indexed in Pubmed: 10754092.

7. Knop MT, Białkowski J, Szkutnik M, et al. Transcatheter closure of atrial septal defects type 2 in children under three years of age. Kardiol Pol. 2018; 76(8): 1257-1262, doi: 10.5603/KP.a2018.0113, indexed in Pubmed: 29862489.

8. Knop M, Szkutnik M, Fiszer R, et al. Transcatheter closure of atrial septal defect in children up to $10 \mathrm{~kg}$ of body weight with Amplatzer device. Cardiol J. 2014; 21(3): 279-283, doi: 10.5603/CJ.a2013.0120, indexed in Pubmed: 23990191.

9. McMahon CJ, Feltes TF, Fraley JK, et al. Natural history of growth of secundum atrial septal defects and implications for transcatheter closure. Heart. 2002; 87(3): 256-259, indexed in Pubmed: 11847166.

10. Fiszer R, Szkutnik M, Chodór B, et al. Spontaneous closure of a large atrial septal defect in an infant. Postepy Kardiol Interwencyjnej. 2014; 10(4): 264-266, doi: 10.5114/pwki.2014.46768, indexed in Pubmed: 25489320.

11. Xu XD, Liu SX, Zhao XX, et al. Comparison of medium-term results of transcatheter correction versus surgical treatment for secundum type atrial septal defect combined with pulmonary valve stenosis. Int Heart J. 2014; 55(4): 326-330, indexed in Pubmed: 24898601

Cite this article as: Smerdziński S, Białkowski J, Szkutnik M, et al. Long-term effects of combined percutaneous atrial septal defect occlusion and pulmonary valvuloplasty in children < 2.5 years old. Kardiol Pol. 2019; 77(1): 53-55, doi: 10.5603/KP.a2018.0226. 